\title{
Prevention of Buttock Claudication by Preserving Antegrade Bilateral Superior Gluteal Arterial Blood Flow in EVAR for Aorto-lliac Aneurysm Accompanied by Bilateral Internal Iliac Artery Aneurysms
}

\author{
Yuta Tajima, MD, PhD, Hitoshi Goto, MD, PhD, Daijiro Akamatsu, MD, PhD, \\ Fukashi Serizawa, MD, PhD, Shunya Suzuki, MD, PhD, Shinichiro Horii, MD, PhD, \\ Norinobu Ogasawara, MD, Hirokazu Takahashi, MD, Yohei Nagaoka, MD, and \\ Takashi Kamei, MD, PhD
}

\begin{abstract}
Buttock claudication (BC) is a complication of surgery for aorto-iliac aneurysms (AIAs) caused by sacrificing blood flow in the internal iliac artery (IIA). However, the preservation of antegrade blood flow of IIAs is often challenging when performing both open surgery and endovascular aneurysm repair (EVAR) for AIAs accompanied by IIA aneurysms. We performed EVAR and successfully preserved the antegrade blood flow of bilateral superior gluteal arteries using the GORE EXCLUDER iliac branch endoprosthesis with the VIABAHN endograft. BC did not occur, both subjectively and objectively, after surgery. This approach can be minimally invasive yet an effective procedure to prevent BC.
\end{abstract}

Keywords: EVAR for internal iliac aneurysm, buttock claudication, IBE

\section{Introduction}

Buttock claudication (BC) is a complication that occurs after surgery to repair aorto-iliac aneurysms (AIAs)

Department of Surgery, Tohoku University Hospital, Sendai, Miyagi, Japan

Received: August 31, 2021; Accepted: November 18, 2021 Corresponding author: Yuta Tajima, MD, PhD. Department of Surgery, Tohoku University Hospital, 1-1 Seiryo-cho, Aoba-ku, Sendai, Miyagi 980-8574, Japan

Tel: +81-22-717-7214, Fax: +81-22-717-7217

E-mail: yuta.tajima.a6@tohoku.ac.jp

(cc) BY-NC-SA (C2022 The Editorial Committee of Annals of Vascular Diseases. This article is distributed under the terms of the Creative Commons Attribution License, which permits use, distribution, and reproduction in any medium, provided the credit of the original work, a link to the license, and indication of any change are properly given, and the original work is not used for commercial purposes. Remixed or transformed contributions must be distributed under the same license as the original. caused by sacrificing blood flow in the internal iliac artery (IIA). ${ }^{1,2)}$ However, the preservation of antegrade blood flow of IIAs is often difficult when performing open surgery and endovascular aneurysm repair (EVAR), as AIAs are accompanied by large internal iliac artery aneurysms (IIAAs), and consequently, the possibility of BC increases, especially for bilateral IIAAs. ${ }^{3)}$ Herein, we report a case of AIAs accompanied by bilateral IIAAs wherein postoperative BC was successfully prevented by performing EVAR while preserving the antegrade blood flow of bilateral superior gluteal arteries (SGAs) using the GORE EXCLUDER iliac branch endoprosthesis (IBE; W. L. Gore and Associates, Flagstaff, AZ, USA) with the VIABAHN endograft (W. L. Gore and Associates).

\section{Case Report}

A 67-year-old man with hypertension and chronic atrial fibrillation taking oral direct oral anticoagulants was referred to our hospital for AIA surgery. He was an active person who enjoyed skiing and walking.

Computed tomography (CT) revealed a $38-\mathrm{mm}$ abdominal aortic aneurysm (AAA), 37-mm right common iliac artery aneurysm (CIAA), 28-mm left CIAA, 45-mm right IIAA, and 45-mm left IIAA (Fig. 1A).

The proximal neck length was $33.5 \mathrm{~mm}$, length of the AAA was $90.7 \mathrm{~mm}$, length of the right common iliac artery (CIA) was $81.1 \mathrm{~mm}$, and length of the left CIA was $60.6 \mathrm{~mm}$ (Fig. 1B). All measurements satisfied the anatomical indications of EVAR using bilateral IBE. ${ }^{3)}$ On both sides, the SGA and inferior gluteal artery (IGA) branched separately from the IIAA. We decided to perform EVAR and use IBE with the VIABAHN endograft to avoid BC by preserving the antegrade blood flow of bilateral SGAs 
Tajima $Y$, et al.

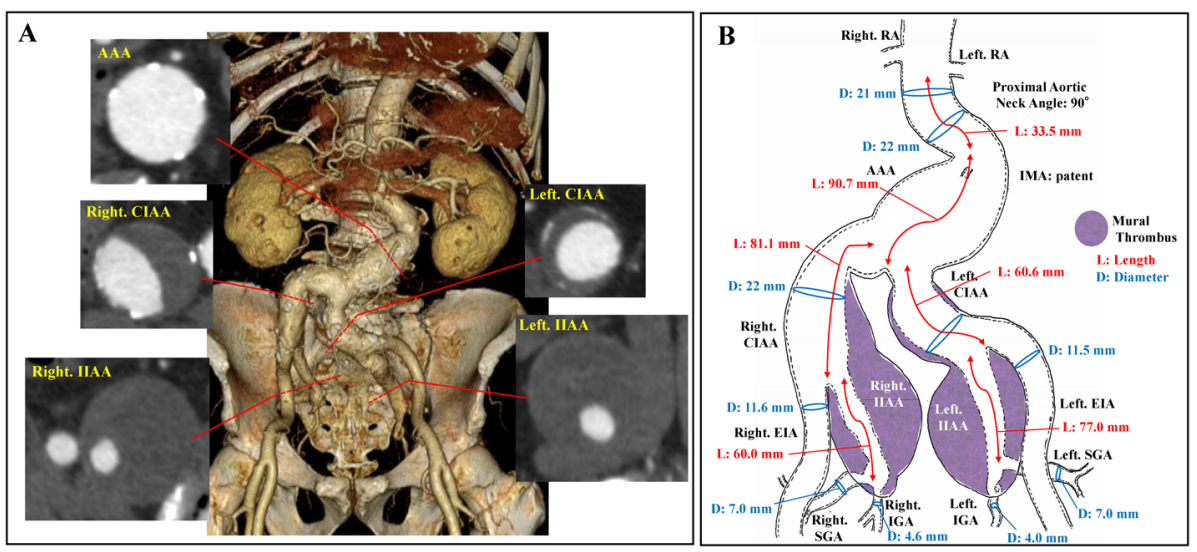

Fig. 1 Preoperative images. (A) Volume-rendering image and cross-sectional view of each aneurysm in enhanced computed tomography. (B) Schema of sizing for endovascular aneurysm repair.

AAA: abdominal aortic aneurysm; CIAA: common iliac artery aneurysm; IIAA: internal iliac artery aneurysm; IMA: inferior mesenteric artery; SGA: superior gluteal artery; IGA: inferior gluteal artery
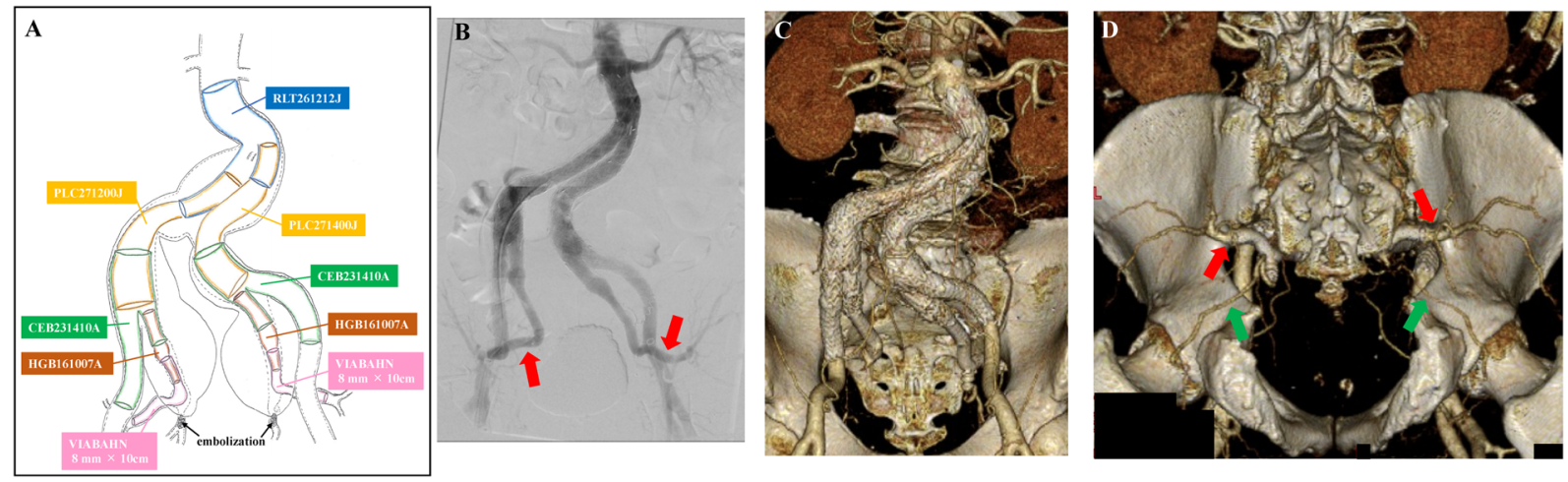

Fig. 2 Postoperative images. (A) Schema of the operation. (B) Contrast-enhanced imaging. Red arrows, good patency was observed in bilateral superior gluteal arteries. (C) Front view of volume-rendering image in enhanced computed tomography. (D) Rear view of volume-rendering image in enhanced computed tomography.

Red arrows: good patency was observed in bilateral superior gluteal arteries; green arrows: the collateral flow of inferior gluteal arteries from the deep femoral arteries

(7.0 mm thick).

Under general anesthesia, we performed the EVAR approach via bilateral common femoral arteries by bilateral femoral incision. We placed an iliac branch component (IBC, CEB231410A) in the left CIA and embolized the iliolumbar arteries and IGA branching from the left IIAA to prevent type II endoleaks. Then, we inserted the VIABAHN endograft (self-expanding type, $8 \mathrm{~mm} \times 10 \mathrm{~cm}$ ) from the left IIAA to the SGA and inserted an internal iliac component (IIC, HGB161007A) to bridge the IBC and VIABAHN endograft. Likewise, we placed an IBC (CEB231410A) in the right CIA and embolized the iliolumbar arteries and IGA branching from the right IIAA. Then, we inserted the VIABAHN endograft (selfexpanding type, $8 \mathrm{~mm} \times 10 \mathrm{~cm}$ ) from the right IIAA to the SGA and inserted an IIC (HGB161007A). Thereafter, we inserted the Gore Excluder C3 (W. L. Gore and Associates) main body (RLT261212J) from the right side. We inserted the contralateral leg (PLC271400J) to bridge the main body and left IBC. Finally, we inserted the contralateral leg (PLC271200J) to bridge the main body and right IBC (Fig. 2A). In contrast-enhanced imaging, a type II endoleak from the lumbar artery was observed in the AAA, no endoleak was observed in bilateral CIAAs or IIAAs, and good patency was observed in bilateral SGAs (Fig. 2B). The operation time was $422 \mathrm{~min}$, fluoroscopy time was $171 \mathrm{~min}$, contrast dose was $225 \mathrm{~mL}$, and blood loss volume was $444 \mathrm{~mL}$.

On the first day after surgery, the patient started eating and walked freely in the ward, and we added aspirin administered orally to prevent VIABAHN endograft occlusion and allow the continuation of direct oral anticoagu- 
lant therapy. Contrast-enhanced CT on day 7 after surgery revealed a type II endoleak in the AAA. However, no endoleak was observed in the CIAAs or IIAAs, and good patency was observed in bilateral SGAs (Figs. 2C and 2D). On day 8 after surgery, the patient was discharged with no BC. A treadmill exercise test using near-infrared spectros- copy and a 6-min walk test were performed on the day before surgery and days 7 and 30 postoperatively (Table 1a). On postoperative days 7 and 30, no symptoms of BC were noted. At 6 months postoperatively, good patency of bilateral SGAs was observed, CIAAs and IIAAs slightly shrank, and AAA did not expand. The patient could enjoy

Table 1a Result of the treadmill exercise test using near-infrared spectroscopy and 6-min walk test

\begin{tabular}{|c|c|c|c|c|c|c|c|c|c|c|c|}
\hline & \multicolumn{8}{|c|}{$\begin{array}{l}\text { Treadmill with near-infrared spectroscopy (NIRO-200NX, HAMAMATSU) (speed: } 2.4 \mathrm{~km} / \mathrm{h} \text {, } \\
\text { tilt angle: } 12 \% \text {, probe position: bilateral buttocks } 5 \mathrm{~cm} \text { behind each greater trochanter) }\end{array}$} & \multicolumn{3}{|c|}{$\begin{array}{l}\text { 6-min walk test } \\
\text { on a flat surface }\end{array}$} \\
\hline & \multirow{2}{*}{\multicolumn{2}{|c|}{$\begin{array}{c}\text { At rest } \\
\text { Buttock TOI } \\
(\%)\end{array}$}} & \multirow{3}{*}{ PWD } & \multicolumn{5}{|c|}{ MWD } & \multirow{3}{*}{$\begin{array}{l}\text { Time } \\
(\mathrm{s})\end{array}$} & \multirow{3}{*}{$\begin{array}{l}\text { MWD } \\
(\mathrm{m})\end{array}$} & \multirow{3}{*}{$\mathrm{BC}$} \\
\hline & & & & \multirow{2}{*}{$\begin{array}{c}\text { Time } \\
(\mathrm{s})\end{array}$} & \multirow{2}{*}{$\begin{array}{l}\text { Distance } \\
\qquad(\mathrm{m})\end{array}$} & \multicolumn{2}{|c|}{$\begin{array}{l}\text { Buttock TOI }(\%) / \\
\text { recovery time }(\mathrm{s})^{*}\end{array}$} & \multirow{2}{*}{$\begin{array}{c}\text { Dissociation } \\
\text { of } \Delta \mathrm{O}_{2} \mathrm{Hb} \text { and } \\
\Delta \mathrm{HHb}\end{array}$} & & & \\
\hline & Right & Left & & & & Right & Left & & & & \\
\hline Before surgery & 72 & 78 & No pain & 180 & 117 & $60 / 179$ & $70 / 190$ & None & 360 & 441 & None \\
\hline Day 7 & 69 & 76 & No pain & 180 & 117 & $59 / 238$ & $70 / 162$ & None & 360 & 459 & None \\
\hline Day 30 & 51 & 58 & No pain & 180 & 117 & $46 / 189$ & $59 / 197$ & None & 360 & 502 & None \\
\hline
\end{tabular}

*Time from the end of walking to returning to the resting TOI.

TOI: tissue oxygenation index; PWD: pain-free walking distance; MWD: maximum walking distance; $\mathrm{O}_{2} \mathrm{Hb}$ : oxygenated hemoglobin; $\mathrm{HHb}$ : deoxyhemoglobin; BC: buttock claudication

Table 1b Presence or absence of a network of the superior gluteal artery (SGA) and inferior gluteal artery (IGA) and buttock claudication after surgery in 20 patients who underwent EVAR combined with bilateral IIA embolization from 2016 to 2020 and this case

\begin{tabular}{|c|c|c|c|c|c|c|c|c|}
\hline \multirow[t]{2}{*}{ Patient } & \multirow[t]{2}{*}{ Age } & \multirow[t]{2}{*}{ Sex } & \multirow{2}{*}{$\begin{array}{c}\text { Preoperative } \\
\text { performance } \\
\text { status }\end{array}$} & \multirow[t]{2}{*}{ Aneurysm } & \multicolumn{2}{|c|}{$\begin{array}{l}\text { Preservation of network } \\
\text { of SGA and IGA }\end{array}$} & \multicolumn{2}{|c|}{$\begin{array}{c}\text { Buttock claudication } \\
\text { after surgery }\end{array}$} \\
\hline & & & & & Right & Left & Right & Left \\
\hline 1 & 69 & Male & 2 & AAA with short Bil. CIA & + & + & - & - \\
\hline 2 & 80 & Male & 1 & AAA with short Bil. CIA & + & + & + & + \\
\hline 3 & 85 & Male & 2 & AAA with short Bil. CIA & + & + & - & + \\
\hline 4 & 80 & Male & 1 & AAA with short Bil. CIA & + & + & - & - \\
\hline 5 & 77 & Male & 2 & AAA, Bil.CIAA & + & + & - & - \\
\hline 6 & 76 & Male & 1 & AAA, short Rt. CIA, Lt. CIAA & + & + & + & + \\
\hline 7 & 80 & Female & 2 & AAA, Bil. CIAA, Bil. IIAA & + & + & + & + \\
\hline 8 & 75 & Male & 2 & AAA with short Lt. CIA, Rt. CIAA & + & + & - & - \\
\hline 9 & 80 & Female & 1 & AAA, Bil. CIAA & + & + & - & - \\
\hline 10 & 83 & Male & 2 & AAA, Bil. CIAA & - & + & + & + \\
\hline 11 & 81 & Male & 1 & AAA, Bil. IIAA & + & - & + & + \\
\hline 12 & 76 & Male & 2 & AAA, Rt. IIAA, Lt. CIAA & - & + & + & + \\
\hline 13 & 72 & Male & 1 & AAA, Rt. CIAA, Lt. IIAA & + & - & - & - \\
\hline 14 & 94 & Male & 1 & Bil. CIAA & - & + & + & + \\
\hline 15 & 87 & Male & 2 & AAA, Bil. CIAA & + & - & + & + \\
\hline 16 & 87 & Male & 2 & AAA with short Bil. CIA & - & + & - & - \\
\hline 17 & 67 & Male & 2 & AAA with short Rt. CIA, Lt. IIAA & + & - & + & + \\
\hline 18 & 83 & Male & 1 & Bil. IIAA & - & - & - & - \\
\hline 19 & 72 & Male & 1 & Bil. CIAA, Bil. IIAA & - & - & + & + \\
\hline 20 & 80 & Male & 2 & AAA, Bil. ॥AA & - & - & + & + \\
\hline This case & 67 & Male & 0 & AAA, Bil. CIAA, Bil. IIAA & $-*$ & $-*$ & - & - \\
\hline
\end{tabular}

*Preservation of antegrade flow of bilateral SGA.

EVAR: endovasucular aneurysm repair; IIA: internal iliac artery; AAA: abdominal aortic aneurysm; Bil: bilateral; CIA: common iliac artery; CIAA: common iliac artery aneurysm; Rt: right; Lt: left; IIAA: internal iliac artery aneurysm 
Tajima Y, et al.

skiing and walking and was highly satisfied.

\section{Discussion}

$\mathrm{BC}$ has been reported to develop on the affected side in $28 \%$ of surgeries when unilateral IIA blood flow is sacrificed. ${ }^{4)}$ Previous studies have also reported that the possibilities of $\mathrm{BC}$ on at least one side increase to $\geq 50 \%$, and the rate of permanent damage increases when bilateral IIA blood flow is sacrificed. ${ }^{4,5}$ These rates have been reported to increase further when the blood flow network of the SGA and IGA is interrupted. $\left.{ }^{5}\right)$

At our institution, 20 patients with AIA, excluding ruptured cases, underwent EVAR combined with bilateral IIA embolization, a few days before EVAR, between 2016 and 2020. Although sigmoid colon ischemia and paraplegia did not occur and their performance status was not high, BC occurred on at least one side in $12(60 \%)$ patients. Among the 20 patients, the blood flow network of the SGA and IGA was preserved on both sides in nine patients, on one side in eight patients, and sacrificed on both sides in three patients, and BC occurred in four $(44 \%)$, six $(75 \%)$, and two $(67 \%)$ patients, respectively (Table $1 \mathrm{~b}$ ). In this case, the patients' preoperative performance status was very high, and $\mathrm{BC}$ was predicted to highly likely occur if we had performed EVAR with bilateral IIA embolization because the blood flow network of each SGA and IGA was likely to be obstructed. Furthermore, BC was predicted to have a significant effect on the patient's activities of daily living and quality of life, as the patient was a relatively young and highly active person. Therefore, we decided to preserve the blood flow of the IIA.

Methods of preserving the blood flow of the IIA in AIA surgery include reconstruction by open surgery, EVAR with external iliac artery-IIA bypass, and EVAR using an iliac branched device including IBE. 6,7) However, these methods are problematic for AIAs when accompanied by large IIAAs. If open surgery were to be employed in this case, reconstruction of either the SGA or IGA would have been technically demanding and invasive. ${ }^{3)}$ This case satisfied the anatomic requirements for the placement of IBC and IIC; therefore, we considered the antegrade blood flow preservation of the branches of IIA with IBE using the VIABAHN endograft feasible and selected minimally invasive EVAR. ${ }^{8)}$ We decided to use IBE and the VIABAHN endograft bilaterally because blood flow was expected to be insufficient if the antegrade blood flow of the SGA or IGA only on one side was preserved. We preserved the blood flow of the SGAs because the SGAs on both sides were thicker than that of the IGAs, and there were good networks between IGAs and deep femoral arteries. To prevent type II endoleaks into the IIAAs, bilateral IGAs and iliolumbar arteries were embolized. When the
VIABAHN endograft is placed, dual antiplatelet therapy is preferable in principle; however, we prescribed single antiplatelet therapy only because the patient was receiving direct oral anticoagulants since before the surgery.

As an objective evaluation of $\mathrm{BC}$, a treadmill exercise test using near-infrared spectroscopy and a 6-min walk test on a flat surface are performed..$^{9,10)}$ However, we could not find a report that performed an objective evaluation of BC after surgery for AIA accompanied by bilateral IIAAs that preserved the blood flow of SGAs. In this case, $\mathrm{BC}$ was not found during the tests, and there were no decreases in the maximum walking distance and the 6-min walk distance on a flat surface. Furthermore, no BC was observed even after discharge; therefore, we concluded that deterioration of the quality of daily life and activities of daily living due to $\mathrm{BC}$ could be prevented.

Data from this case alone are insufficient to answer how much preservation of antegrade blood flow of bilateral SGAs contributed to the prevention of BC. We cannot rule out the possibility that $\mathrm{BC}$ was preventable even if the SGA was reconstructed only on one side or if IIA blood flow was not preserved bilaterally; thus, further accumulation of similar cases is desired. The long-term outcome of this procedure is unclear, and cautious follow-up, including migration of the device, endoleaks, aneurysm enlargement, obstruction of the stent-graft legs, and the VIABAHN endografts, is required. Given that this procedure requires expensive devices and complex techniques, we believe that the procedure should be used for carefully selected patients satisfying a high level of preoperative activity and some other conditions in addition to the anatomical conditions. ${ }^{3,4)}$ We recommended preserving the antegrade blood flow to bilateral SGAs (or IGAs) to prevent $\mathrm{BC}$ in cases that need embolization of bilateral SGAs and IGAs individually so that the bilateral blood flow network of the SGA and IGA is interrupted to exclude AIAs in conventional EVAR for very active patients.

\section{Conclusion}

EVAR for AIA accompanied by bilateral IIAAs using IBE with the VIABAHN endograft to preserve antegrade blood flow of bilateral SGAs is a minimally invasive yet effective procedure to prevent $\mathrm{BC}$ in selected cases.

\section{Funding}

Not applicable

\section{Patient Consent for Publications}

We obtained the patient's consent for publication. 


\section{Ethical Approval for Research}

This study was approved by the ethical committee of Tohoku University Hospital (approval number: 22812).

\section{Disclosure Statements}

The authors have no financial conflicts of interest to disclose.

\section{Author Contributions}

Study conception: YT

Data collection: all authors

Investigation: YT

Writing: YT

Critical review and revision: all authors

Final approval of the article: all authors

Accountability for all aspects of the work: all authors

\section{References}

1) Chitragari G, Schlosser FJ, Ochoa Chaar CI, et al. Consequences of hypogastric artery ligation, embolization, or coverage. J Vasc Surg 2015; 62: 1340-7.e1.

2) Shigematsu $H$, Nunokawa M, Hatakeyama T, et al. Inferior mesenteric and hypogastric artery reconstruction to prevent colonic ischaemia following abdominal aortic aneurysmec- tomy. Cardiovasc Surg 1993; 1: 13-8.

3) Rana MA, Kalra M, Oderich GS, et al. Outcomes of open and endovascular repair for ruptured and nonruptured internal iliac artery aneurysms. J Vasc Surg 2014; 59: 634-44.

4) Rayt HS, Bown MJ, Lambert KV, et al. Buttock claudication and erectile dysfunction after internal iliac artery embolization in patients prior to endovascular aortic aneurysm repair. Cardiovasc Intervent Radiol 2008; 31: 728-34.

5) Mehta M, Veith FJ, Ohki T, et al. Unilateral and bilateral hypogastric artery interruption during aortoiliac aneurysm repair in 154 patients: a relatively innocuous procedure. J Vasc Surg 2001; 33 Suppl: S27-S32.

6) Maldonado TS, Mosquera NJ, Lin P, et al. Gore Iliac Branch Endoprosthesis for treatment of bilateral common iliac artery aneurysms. J Vasc Surg 2018; 68: 100-8.e3.

7) Faries PL, Morrissey N, Burks JA, et al. Internal iliac artery revascularization as an adjunct to endovascular repair of aortoiliac aneurysms. J Vasc Surg 2001; 34: 892-9.

8) Cornwall JW, Han DK, Fremed DI, et al. Successful off-label use of the GORE EXCLUDER Iliac Branch Endoprosthesis to preserve gluteal perfusion during staged endovascular repair of bilateral isolated hypogastric aneurysms. Journal of Vascular Surgery Cases and Innovative Techniques 2017; 3: 37-40.

9) Sugano N, Inoue Y, Iwai T. Evaluation of buttock claudication with hypogastric artery stump pressure measurement and near infrared spectroscopy after abdominal aortic aneurysm repair. Eur J Vasc Endovasc Surg 2003; 26: 45-51.

10) Laboratories ATSCoPSfCPF. ATS statement: guidelines for the six-minute walk test. Am J Respir Crit Care Med 2002; 166: 111-7. 